\title{
Electronic properties of spin excitation in multiferroics with a spinel structure: first principles calculation
}

\section{Husnu Koc, Selami Palaz, Amirullah M. Mamedov \& Ekmel Ozbay}

To cite this article: Husnu Koc, Selami Palaz, Amirullah M. Mamedov \& Ekmel Ozbay (2019) Electronic properties of spin excitation in multiferroics with a spinel structure: first principles calculation, Ferroelectrics, 539:1, 41-49, DOI: 10.1080/00150193.2019.1570010

To link to this article: https://doi.org/10.1080/00150193.2019.1570010

\section{Published online: 04 Jun 2019.}

Submit your article to this journal $\widetilde{ }$

\section{Џ Article views: 50}

Q View related articles $\asymp$

View Crossmark data 


\title{
Electronic properties of spin excitation in multiferroics with a spinel structure: first principles calculation
}

\author{
Husnu Koc ${ }^{\mathrm{a}}$, Selami Palaz ${ }^{\mathrm{b}}$, Amirullah M. Mamedov ${ }^{\mathrm{c}, \mathrm{d}}$, and Ekmel Ozbay ${ }^{\mathrm{c}}$ \\ ${ }^{a}$ Faculty of Science and Letters Department of Physics, Siirt University, Siirt, Turkey; ${ }^{b}$ Faculty of Sciences \\ Department of Physics, Harran University, Sanliurfa, Turkey; ' Nanotechnology Research Center Bilkent \\ University, Bilkent, Ankara, Turkey; ${ }^{\mathrm{B} B a k u}$ State University International Scientific Center, \\ Baku, Azerbaijan
}

\begin{abstract}
In the present work, the structural, electronic and mechanical properties of $\mathrm{LiVCuO}_{4}$ and $\mathrm{LiCu}_{2} \mathrm{O}_{4}$ spinel type multiferroics have been investigated by means of first principles calculations. The spin polarized generalized gradient approximation has been used for modeling exchange-correlation effects. The structural optimization of these multiferroics compounds has been performed by using VASP-code, and the lattice parameters and magnetic moments have been calculated. From our calculation, it has been determined that the $\mathrm{LiVCuO}_{4}$ compound is a narrow band gap semiconductor, while the $\mathrm{LiCu}_{2} \mathrm{O}_{4}$ compound is metallic in nature. Considering the spin states from the electronic band structure and density of the state (DOS) of the $\mathrm{LiVCuO}_{4}$ compound, it has been identified that $\mathrm{E}_{\mathrm{g}}=1.87 \mathrm{eV}$ for spin up and $E_{g}=0.37 \mathrm{eV}$ for spin down. The second-order elastic constants have been calculated, and the other related quantities have also been estimated in the present work.
\end{abstract}

\section{ARTICLE HISTORY}

Received 14 May 2018

Accepted 31 October 2018

\section{KEYWORDS}

Spinel type multiferroics; ab-initio calculations; mechanical properties; electronic properties

\section{Introduction}

Recently, researchers have focused on LiMVO4 $(\mathrm{M}=\mathrm{Cu}, \mathrm{Ni}, \mathrm{Co}, \mathrm{Zn}, \mathrm{Mg}, \mathrm{Be})$ materials that can be used for rechargeable lithium cathode materials to increase the energy density and decrease costs. $\mathrm{LiCuVO}_{4}$ material is understood as a one-dimensional superconductor as a result of the electrical conductivity and heat transfer measurements obtained at low temperature [1-4]. Formulated ternary $\mathrm{AB}_{2} \mathrm{O}_{4}$ oxides are spinel structural materials. Spinel structural materials according to the distribution of atoms $\mathrm{A}$ and $\mathrm{B}$ on the lattice sites can be classified into two distinct kinds deemed normal and inverse spinel, respectively. The atoms $\mathrm{A}$ and $\mathrm{B}$ are characterized as normal spinel by occupying the tetrahedral and octahedral sites, respectively, while some of the B atoms, the A and the remaining $\mathrm{B}$ atoms are characterized as reverse spinel by occupying tetrahedral and octahedral sites, respectively [5]. Since spinel structure materials are considered as battery materials, magnetic materials, superhard materials and luminescent materials, these materials have wide and very important application areas [6-8]. 
Multiferroics are materials where in ferroelectric and ferromagnetic properties are exhibited in a single phase. Since magnetization cannot be controlled by an electric field in a single phase, the coupling between ferromagnetic and ferroelectric is so weak that it cannot contribute to the magnetic transition. Therefore, many multiferroics have a low Curie temperature. Ferromagnetism and ferroelectric loss occur due to weak coupling and a low Curie temperature. Therefore, multiferroic-ferrite composites can be synthesized as a result of high Curie temperature and suitable ferromagnetic-ferroelectric coupling. As a result of the work done, it has been reported that the elastic coupling between multiferrides and spinel ferrites may be formed by epitaxial or layered alignment $[9,10]$.

In the past, some detailed studies on the structural and magnetic properties of these spinel-type multiferroic compounds have been made [4, 5, 11-15]. Lafontaine et al. [11] experimentally investigated the structural properties of orthorhombic $\mathrm{LiCuVO}_{4}$ at room temperature. Prokofiev et al. [12] discussed the magnetic properties of the LiCuVO4 compound using magnetic susceptibility measurements. Kumar et al. [13] investigated the magnetic properties of $\mathrm{Zn}, \mathrm{Co}$, and $\mathrm{Mn}$ doped $\mathrm{LiCuVO}_{4}$ compound with neutron diffraction and X-ray photoemission. They observed that the antiferromagnetic correlation of the compound was increased when doped with $\mathrm{Zn}$ and Co, and it was stimulated when the ferromagnetic order was doped with Mn. Kazakopoulos et al. [4] studied the characterization of the $\mathrm{LiCuVO} 4$ compound prepared at $530{ }^{\circ} \mathrm{C}$ by solid state reaction method. Kegler et al. [14] discussed the anisotropy effects on magnetic resonance spectra in the distorted reverse spinel $\mathrm{LiCuVO}_{4}$ compound using EPR and NMR measurements. Santos et al. [15] investigated the structural and magnetic properties of spinel-structured $\mathrm{Co} 2 \mathrm{MnO} 4$ compound doped with a different conformation of bismuth by X-ray diffraction. Heng-Nan et al. [5] obtained Raman vibration modes and Raman shifts corresponding to these modes under different pressure of the reverse spinel-structured $\mathrm{LiCuVO}_{4}$ compounds by Raman spectroscopy measurements. As far as we know, the physical properties (structural, mechanical, and optical properties) of these compounds have not been studied theoretically until now. In this work, we have investigated the structural, mechanical, and electronic properties of the $\mathrm{LiCuVO}_{4}$ and $\mathrm{LiCu}_{2} \mathrm{O}_{4}$ compounds.

\section{Method of calculation}

In all of our calculations that were performed using the ab-initio total-energy and molecular-dynamics program VASP (Vienna ab-initio simulation program) [16-19] that was developed within the density functional theory (DFT) [20], the exchange-correlation energy function is treated within a spin polarized GGA (generalized gradient approximation) by the density functional of Perdew et al. [21]. The potentials used for the GGA calculations take into account the $1 \mathrm{p}^{2} 2 \mathrm{~s}^{1}$ valence electrons of each Li-, $3 \mathrm{p}^{6} 3 \mathrm{~d}^{10} 4 \mathrm{~s}^{1}$ valence electrons of each $\mathrm{Cu}-, 2 \mathrm{~s}^{2} 2 \mathrm{p}^{4}$ valence electrons of each O-, and $3 \mathrm{p}^{6} 3 \mathrm{~d}^{3} 4 \mathrm{~s}^{2}$ valence electrons of each $\mathrm{V}$ - atoms. When including a plane-wave basis up to a kineticenergy cutoff equal to $20.36 \mathrm{Ha}$ for $\mathrm{LiCu}_{2} \mathrm{O}_{4}$ and $23.38 \mathrm{Ha}$ for $\mathrm{Li}(\mathrm{VCu}) \mathrm{O}_{4}$, the properties investigated in this work are well converged. The Brillouin-zone integration was performed using special $\mathrm{k}$ points sampled within the Monkhorst-Pack scheme [22]. We 
Table 1. The calculated equilibrium lattice parameters $(a, b$, and $c)$ together with the experimental values and total magnetic moment $\left(\mu\right.$, in $\mu_{\mathrm{B}} /$ f.u.) for $\mathrm{LiVCuO}_{4}$ and $\mathrm{LiCu}_{2} \mathrm{O}_{4}$ compounds

\begin{tabular}{lllllll}
\hline Material & $\mathrm{a}(\AA)$ & $\mathrm{b}(\AA)$ & $\mathrm{c}(\AA)$ & $\mathrm{V}_{0}\left(\AA^{3}\right)$ & $\mu$ & Refs. \\
\hline $\mathrm{LiVCuO}_{4}$ & 5.687 & 5.796 & 9.011 & 297.02 & 2.00 & Present \\
& 5.662 & 5.809 & 8.758 & 288.0 & & Exp. [11] \\
& 5.652 & 5.800 & 8.745 & 286.68 & & Exp. [13] \\
& & & & & $1.84-1.97$ & Exp. [12] \\
& & & & & 1.88 & Exp. [23] \\
LiCu2O $_{4}$ & 5.631 & 5.919 & 8.318 & 277.17 & 2.82 & \\
\hline
\end{tabular}

Table 2. The calculated elastic constants (in $\mathrm{GPa}$ ) for $\mathrm{LiVCuO}_{4}$ and $\mathrm{LiCu}_{2} \mathrm{O}_{4}$ compounds

\begin{tabular}{|c|c|c|c|c|c|c|c|c|c|c|}
\hline Material & Reference & $C_{11}$ & $C_{12}$ & $\mathrm{C}_{13}$ & $\mathrm{C}_{22}$ & $\mathrm{C}_{23}$ & $C_{33}$ & $\mathrm{C}_{44}$ & $\mathrm{C}_{55}$ & $\mathrm{C}_{66}$ \\
\hline $\mathrm{LiVCuO}_{4}$ & Present & 294.3 & 89.1 & 92.7 & 371.1 & 136.7 & 151.1 & 55.2 & 121.1 & 82.5 \\
\hline $\mathrm{LiCu}_{2} \mathrm{O}_{4}$ & Present & 190.8 & 88.6 & 79.8 & 208.4 & 101.8 & 265.9 & 37.4 & 78.4 & 64.1 \\
\hline
\end{tabular}

found that a mesh of $8 \times 8 \times 8 \mathrm{k}$ points and $7 \times 7 \times 7 \mathrm{k}$ point for $\mathrm{LiCu}_{2} \mathrm{O}_{4}$ and $\mathrm{Li}(\mathrm{VCu}) \mathrm{O}_{4}$, respectively was required to describe the structural, mechanical, and electronic properties.

\section{Result and discussion}

$\mathrm{LiCuVO}_{4}$ and $\mathrm{LiCu}_{2} \mathrm{O}_{4}$ compounds have an orthorhombic structure with the Imma (No. 74) space group. There are 4 molecules (28 atoms) in the unit cell of this crystal structure. Before starting the calculations, we performed the optimization process using the experimental structural parameters (lattice constants and atomic positions) for these compounds. The calculated lattice parameters are given in Table 1 together with the experimental values. The lattice parameters calculated for the $\mathrm{LiCuVO}_{4}$ compound are in good agreement with the experimental values $[11,13]$ approx. $0.1-1.5 \%$. The total magnetic moments obtained for $\mathrm{LiCuVO}_{4}$ and $\mathrm{LiCu}_{2} \mathrm{O}_{4}$ are 2.00 and 2.82, respectively. The magnetic moment value obtained for the $\mathrm{LiCuVO}_{4}$ compound is close to the $\mu_{\text {eff }}$ values $[12,23]$ obtained experimentally (see Table 1 ).

Elastic constants are important parameters because they give information about the structural stability of a material. The elastic constants given in Table 2 are calculated using the "strain-stress" technique [24]. Unfortunately, there are no experimental and theoretical results to be compared with the obtained results. Elastic constants calculated for both compounds provide the mechanical stability conditions specified in the Ref. $[25,26]$. The $C_{11}, C_{22}$ and $C_{33}$ elastic constants show resistance to the linear compression in the a-, b-, and c- directions, respectively. The $\mathrm{C}_{22}$ value for the $\mathrm{LiCuVO}_{4}$ compound is higher than the $\mathrm{C}_{11}$ and $\mathrm{C}_{33}$ values. Therefore, the b-axis can be less compressible. The $\mathrm{C}_{33}$ value for the $\mathrm{LiCu}_{2} \mathrm{O}_{4}$ compound is higher than the $\mathrm{C}_{11}$ and $\mathrm{C}_{22}$ values, so the $\mathrm{c}$ axis can be less compressible.

Other polycrystalline elastic properties (Young's modulus, Poisson's ratio, anisotropic factors, sound velocities, the Debye temperature) of polycrystalline bulk modulus and isotropic Shear modules obtained from the Voigt-Reuss-Hill (VRH) approach [27-29] are calculated and given in Table 3 and Table 4. In general, hardness is known as a material parameter that resists elastic and plastic deformation, this parameter is bulk modulus (B) or shear modulus (G). It can be said that the ionic character is dominant 
Table 3. The calculated isotropic bulk modulus ( $B$, in $G P a)$, shear modulus ( $G$, in $G P a)$, Young's modulus ( $\mathrm{E}$, in $\mathrm{GPa}$ ) and Poisson's ratio for $\mathrm{LiVCuO}_{4}$ and $\mathrm{LiCu}_{2} \mathrm{O}_{4}$ compounds

\begin{tabular}{|c|c|c|c|c|c|c|c|c|c|c|c|}
\hline Material & Reference & $\mathrm{B}_{\mathrm{R}}$ & $\mathrm{B}_{\mathrm{v}}$ & $\mathrm{B}_{\mathrm{H}}$ & $G_{R}$ & $\mathrm{G}_{\mathrm{V}}$ & $\mathrm{G}_{\mathrm{H}}$ & $\mathrm{E}$ & v & $\mathrm{G} / \mathrm{B}$ & $\mathrm{B} / \mathrm{G}$ \\
\hline $\mathrm{LiVCuO}_{4}$ & Present & 137.4 & 161.5 & 149.5 & 69.0 & 85.0 & 76.7 & 197.0 & 0.28 & 0.51 & 1.95 \\
\hline $\mathrm{LiCu}_{2} \mathrm{O}_{4}$ & Present & 131.0 & 133.9 & 132.5 & 57.7 & 62.3 & 60.0 & 156.4 & 0.30 & 0.45 & 2.21 \\
\hline
\end{tabular}

Table 4. The calculated anisotropic factors, sound velocities $\left(v_{t}, v_{1}, v_{m}\right)$ the Debye temperatures for $\mathrm{LiVCuO}_{4}$ and $\mathrm{LiCu}_{2} \mathrm{O}_{4}$ compounds

\begin{tabular}{|c|c|c|c|c|c|c|c|c|c|c|}
\hline Material & Reference & $A_{1}$ & $A_{2}$ & $\mathrm{~A}_{3}$ & $\mathrm{~A}_{\text {comp }}(\%)$ & $\mathrm{A}_{\text {shear }}(\%)$ & $v_{t}(\mathrm{~m} / \mathrm{s})$ & $v_{l}(\mathrm{~m} / \mathrm{s})$ & $v_{m}(\mathrm{~m} / \mathrm{s})$ & $\theta_{\mathrm{D}}(\mathrm{K})$ \\
\hline $\mathrm{LiVCuO}_{4}$ & Present & 0.849 & 1.947 & 0.677 & 8.061 & 10.722 & 4301 & 7792 & 4792 & 649 \\
\hline $\mathrm{LiCu}_{2} \mathrm{O}_{4}$ & Present & 0.504 & 1.159 & 1.155 & 1.102 & 3.840 & 3556 & 6691 & 3973 & 551 \\
\hline
\end{tabular}

in the atomic bonding from the calculated Poisson's ratio $\left(v=0.28\right.$ for $\mathrm{LiCuVO}_{4}$ and $v=0.30$ for $\mathrm{LiCu}_{2} \mathrm{O}_{4}$ ) [30-32]. It can also be seen from the $\mathrm{G} / \mathrm{B}$ ratio $(0.51$ for $\mathrm{LiCuVO}_{4}$ and 0.45 for $\mathrm{LiCu}_{2} \mathrm{O}_{4}$ ) where the ionic character dominates (covalent if $\mathrm{G} /$ $\mathrm{B} \approx 1.1$, ionic if $\mathrm{G} / \mathrm{B} \approx 0.6$ ). The Young's modulus $(\mathrm{E})$ is a measure of the stiffness and if the $\mathrm{E}$ value is high, the material is stiffer. The Young's modulus value (197.0) calculated for the $\mathrm{LiCuVO}_{4}$ compound is higher than the value (156.4) of the $\mathrm{LiCu}_{2} \mathrm{O}_{4}$ compound, so the $\mathrm{LiCuVO}_{4}$ compound is expected to be stiffer. If the $\mathrm{B} / \mathrm{G}$ ratio is less (high) than 1.75, the material is brittle (ductile) [33,34]. According to the $B / G$ value, both compounds are ductile.

The elastic anisotropies (A1, A3, A3) calculated for $\mathrm{LiCuVO}_{4}$ and $\mathrm{LiCu}_{2} \mathrm{O}_{4}$ compounds and the percentages of anisotropy in the compression and shear are given in Table 4. The $\mathrm{LiCuVO}_{4}$ compound exhibits low anisotropy compared to the $\mathrm{LiCu}_{2} \mathrm{O}_{4}$ compound. For materials, the $\mathrm{A}_{\text {comp }}(\%)$ and $\mathrm{A}_{\text {shear }}(\%)$ values can range from zero (isotropic) to $100 \%$ representing the maximum anisotropy [35]. The $A_{\text {comp }}(\%)$ and $\mathrm{A}_{\text {shear }}(\%)$ calculated for the $\mathrm{LiCuVO}_{4}$ compound are higher than the $\mathrm{LiCu}_{2} \mathrm{O}_{4}$ compound. The Debye temperature and sound velocities [36-38] calculated for these compounds are given in Table 4 . The calculated Debye temperature value $(649 \mathrm{~K})$ for $\mathrm{LiCuVO}_{4}$ is higher than the calculated Debye temperature value $(551 \mathrm{~K})$ for $\mathrm{LiCu}_{2} \mathrm{O}_{4}$. Generally, the Debye temperature is small for soft materials and large for hard materials. Therefore, it can be said that both compounds are hard materials, but the $\mathrm{LiCuVO}_{4}$ compound is harder than the $\mathrm{LiCu}_{2} \mathrm{O}_{4}$ compound.

Spin-polarized electronic band structures and density of states have been calculated using the GGA approach for both compounds in the orthorhombic structure and given in Figs. 1-3. The high symmetry points $(\Gamma-\mathrm{T}-\mathrm{S}-\mathrm{W}-\mathrm{R})$ of the Brillouin zone are used in electronic band structure calculations. Fermi level is selected as the zero energy level although it is not specified in Fig. 1. The $\mathrm{E}_{\mathrm{g}}$ values for both compounds are determined from the electronic band structure data. $\mathrm{LiCuVO}_{4}$ compound is a narrow band gap $\left(0.13 \mathrm{eV}\right.$-indirect) semiconductor in nature and the $\mathrm{LiCu}_{2} \mathrm{O}_{4}$ compound is also metallic. Considering the spin polarized electronic band structure of the $\mathrm{LiCuVO}_{4}$ compound, it has been identified as $\mathrm{E}_{\mathrm{g}}=1.87$ (indirect) $\mathrm{eV}$ for spin up and $\mathrm{E}_{\mathrm{g}}=0.37$ (indirect) $\mathrm{eV}$ for spin down (see Fig. 1a). The valence band maximum (VBM) of the $\mathrm{LiCuVO}_{4} \mathrm{com}$ pound is located at the $S$ point, while the conduction band minimum (CBM) is located almost midway between $\mathrm{W}-\Gamma$. In the spin polarized $\mathrm{LiCuVO}_{4}$ compound, $\mathrm{VBM}$ for spin 

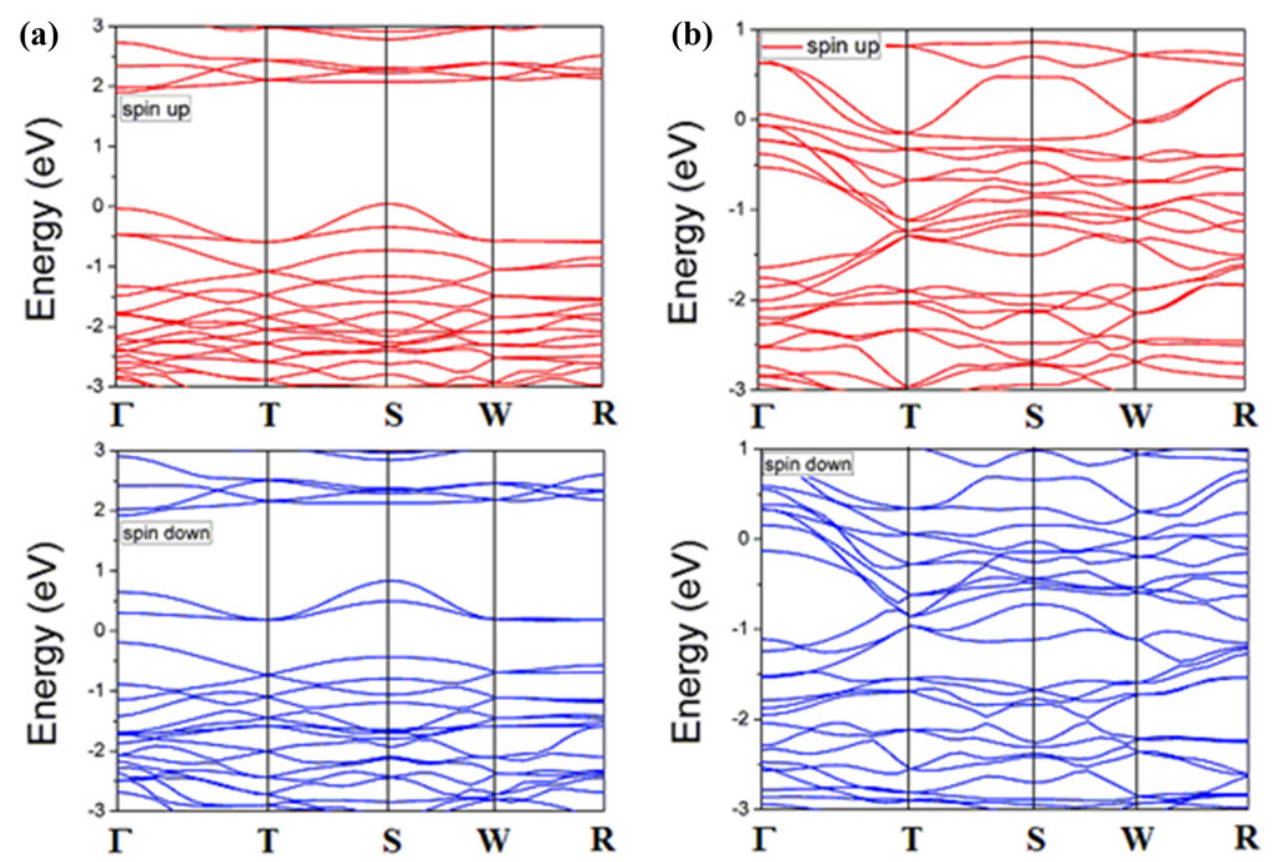

Figure 1. The calculated electronic band structures for the spin up and spin down of a) $\mathrm{LiCuVO}_{4}$ and b) $\mathrm{LiCu}_{2} \mathrm{O}_{4}$ compounds.
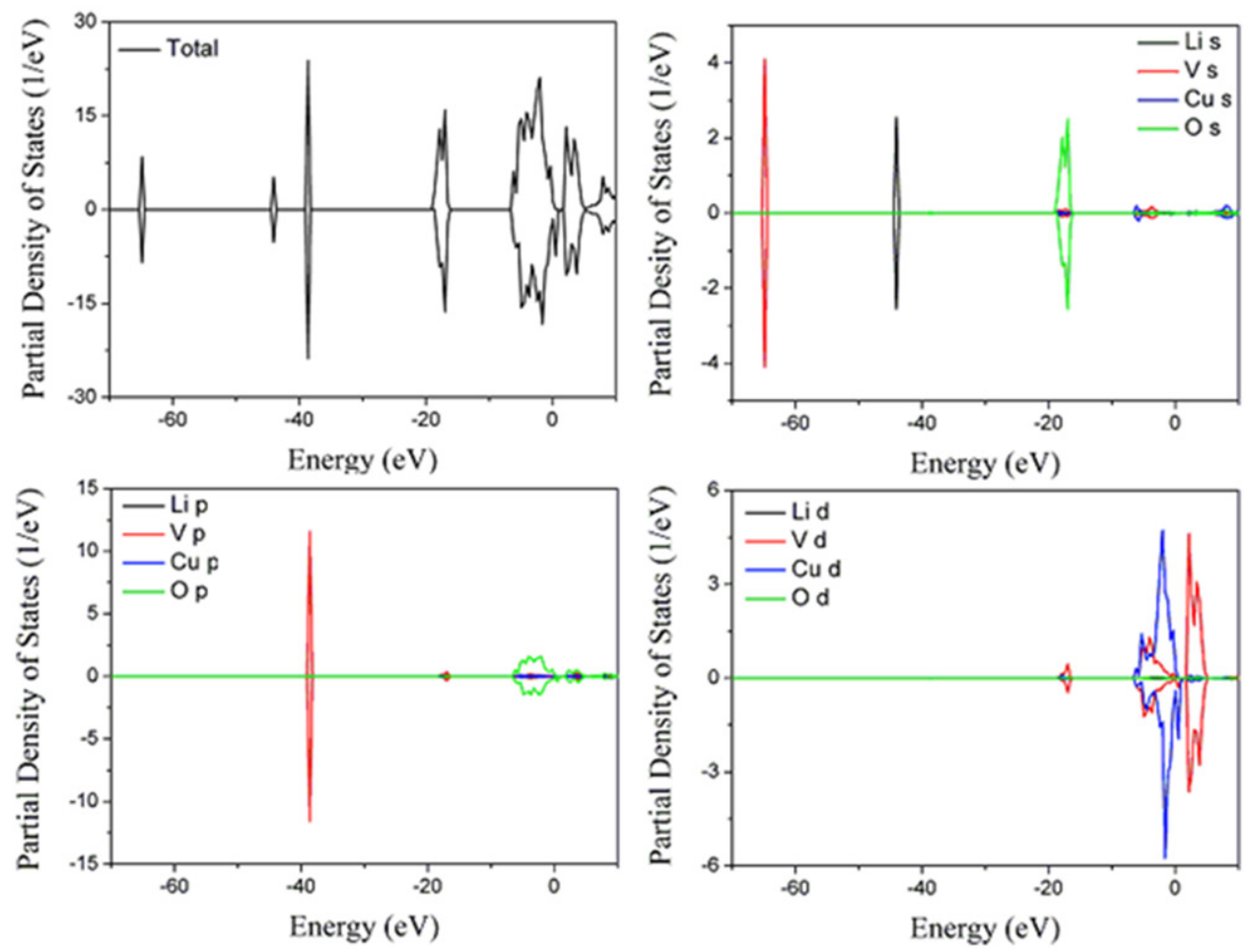

Figure 2. The spin-polarized total and projected density of states for $\mathrm{LiCuVO}_{4}$ compound. 

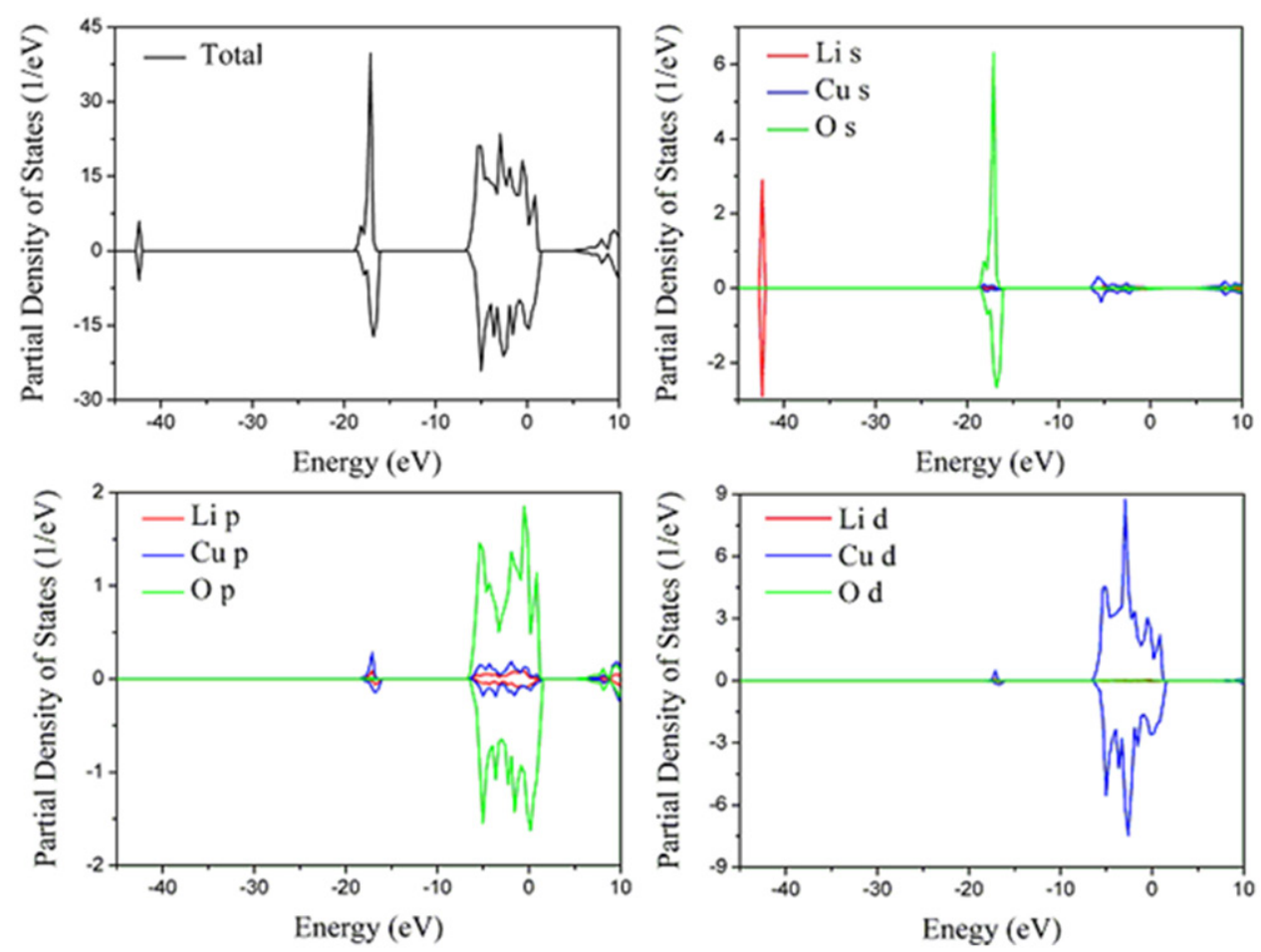

Figure 3. The spin-polarized total and projected density of states for $\mathrm{LiCu}_{2} \mathrm{O}_{4}$ compound.

up is located at the $S$ point and CBM is located at the $\Gamma$ point, while VBM for spin down is located at the S point and CBM is located almost midway between $\mathrm{W}-\Gamma$.

The spin polarized total and partial densities of states are calculated to analyze the basic electronic components of the band structures of the $\mathrm{LiCuVO}_{4}$ and $\mathrm{LiCu}_{2} \mathrm{O}_{4}$ compounds and are given in Figs. 2 and 3, respectively. As shown in Figs. 2 and 3, there are 5 and 3 different energy ranges for the $\mathrm{LiCuVO}_{4}$ and $\mathrm{LiCu}_{2} \mathrm{O}_{4}$ compounds below the Fermi level, respectively. The energy region between -39 and $-37 \mathrm{eV}$ is occupied by $\mathrm{V}$ p states while the lowest energy region of the $\mathrm{LiCuVO}_{4}$ compound is occupied by $\mathrm{V}$ s states. The energy region between -45 and $-44 \mathrm{eV}$ for both compounds is occupied by $\mathrm{Li} s$ states. The energy region between -19 and $-16 \mathrm{eV}$ for both compounds is dominated by $\mathrm{V}$ p states with a small amount of $\mathrm{Cu} s$ states. The upper valence bands for both compounds can be divided into two parts: The higher energy region of the $\mathrm{LiCuVO}_{4}$ compound is dominated by $\mathrm{V}$ d states, while the lower valence bands are dominated by the hybridization of $\mathrm{V} \mathrm{d}$ and $\mathrm{Cu} d$ states. The lower valence bands of the $\mathrm{LiCu}_{2} \mathrm{O}_{4}$ compound are dominated by the hybridization of the $\mathrm{O} p$ and $\mathrm{Cu} d$ states by a slight hybridization of the $\mathrm{Li} \mathrm{p}$ and $\mathrm{Cu} \mathrm{p}$ states, while the upper valence bands are dominated by the hybridization of the $\mathrm{O} p$ and $\mathrm{Cu} d$ states (but the contribution from the states of $\mathrm{Cu} \mathrm{d}$ is greater than the contribution from $\mathrm{O} p$ states). The lowest unoccupied conduction bands just above the Fermi level are dominated by the $\mathrm{Cu} \mathrm{d}$ states of the $\mathrm{LiCu}_{2} \mathrm{O}_{4}$ compound while the $\mathrm{LiCuVO}_{4}$ compound is dominated by the $\mathrm{V} \mathrm{d}$ states. 


\section{Conclusion}

In this work, the structural, electronic and mechanical properties of $\mathrm{LiCuVO}_{4}$ and $\mathrm{LiCu}_{2} \mathrm{O}_{4}$ spinel type multiferroics have been calculated using the ab initio method. Spin polarized GGA approximation has been used in the calculations. The obtained lattice parameters values as a result of optimization are compared with the existing literature values, and it is seen that they are in agreement with these values. In electronic structure calculations, the $\mathrm{LiCuVO}_{4}$ compound is indirect narrow gap semiconductor in nature and the $\mathrm{LiCu}_{2} \mathrm{O}_{4}$ compound is also a metallic character. The calculated elastic constants provide the mechanical stability conditions. In addition, the calculated mechanical properties (bulk modulus, Shear modulus, Poisson's ratio, Young's modulus etc.) indicate that these compounds are ionic, rigid, and isotropic materials.

\section{Funding}

This work is supported by the projects DPT-HAMIT and NATO-SET-193, and one of the authors (Ekmel Ozbay) also acknowledges partial support from the Turkish Academy of Sciences.

\section{References}

[1] A. Kazakopoulos, and O. Kalogirou, Impedance spectroscopy study of $\mathrm{LiCuVO}_{4}$. Solid State Ionics. 179(21-26), 936 (2008). DOI: 10.1016/j.ssi.2007.12.084.

[2] L.S. Parfen'eva et al., Heat transport over nonmagnetic lithium chains in $\mathrm{LiCuVO}_{4}$, a new one-dimensional superionic conductor. Phys. Solid State. 2003; 45(11): 2093. DOI: $10.1134 / 1.1626742$.

[3] L.S. Parfen'eva LS et al., Electrical conductivity and permittivity of the one-dimensional superionic Conductor $\mathrm{LiCuVO}_{4}$. Phys. Solid State. 2004; 46(6): 1027. DOI: 10.1134/ 1.1767238 .

[4] G. T. Fey, and D. L. Huang, Synthesis, characterization and cell performance of inverse spinel electrode materials for lithium secondary batteries. Electrochim Acta. 45(1-2), 295 (1999). DOI: 10.1016/S0013-4686(99)00212-1.

[5] L. Heng-Nan et al., High-pressure effect on inverse spinel $\mathrm{LiCuVO}_{4}$ : X-ray diffraction and Raman scattering. Chin. Phys. B. 22(1), 016103 (2013). DOI: 10.1088/1674-1056/22/1/ 016103.

[6] W. F. J. Fontijn et al., A consistent interpretation of the magneto-optical spectra of spinel type ferrites (invited). J. Appl. Phys. 85(8), 5100 (1999).

[7] A. Zerr et al., Synthesis of cubic siliconnitride. Nature. 400(6742), 340 (1999). DOI: $10.1038 / 22493$.

[8] E. Martinez-Sanchez et al., Cathodoluminescent characteristics of Sm-doped $\mathrm{ZnAl}_{2} \mathrm{O}_{4}$ nanostructured. Phys. Stat. Sol. (a). 202(1), 102 (2005). DOI: 10.1002/pssa.200406906.

[9] M. Fiebig, Revival of the magnetoelectric effect. J. Phys. D: Appl. Phys. 38(8), R123 (2005). DOI: $10.1088 / 0022-3727 / 38 / 8 /$ R01.

[10] M. A. Nazır et al., Structural, electrical, and dielectric properties of multiferroic-spinel ferrite composites. J. Electron. Mater. 45, 1065 (2016). DOI: 10.1007/s11664-015-4286-3.

[11] M. A. Lafontaine, M. Leblanc, and G. Ferey, New refinement of the room-temperature of $\mathrm{LiCuVO}_{4}$. Acta Cryst. C45, 1205 (1989). DOI: 10.1107/S0108270189001551.

[12] A. V. Prokofiev et al., Structure, stoichiometry and magnetic properties of the low-dimensional structure phase $\mathrm{LiCuVO}_{4}$. J. Solid State Chem. 177(9), 3131 (2004). DOI: 10.1016/ j.jssc.2004.05.031. 
[13] A. Kumar et al., Structural and magnetic properties of quasi-dimensional doped $\mathrm{LiCuVO}_{4}$. J. Solid State Chem. 208, 120 (2013). DOI: 10.1016/j.jssc.2013.09.029.

[14] C. Kegler et al., Magnetic resonance on $\mathrm{LiCuVO}_{4}$. Eur. Phys. J. B. 22(3), 321 (2001). DOI: $10.1007 / \mathrm{s} 100510170109$.

[15] M. E. dos Santos et al., Cation distribution and magnetic characterization of the multiferroic cobalt manganese Co2MnO4 spinel doped with bismuth. J. Magn. Magn. Mater. 329, 53 (2013). DOI: 10.1016/j.jmmm.2012.09.070.

[16] G. Kresse, and J. Hafner, Ab initio molecular dynamics for liquid metals. Phys. Rev. B. 47(1), 558 (1993). DOI: 10.1103/PhysRevB.47.558.

[17] G. Kresse, and J. Furthmüller, Ab-initio total energy calculations for metals and semiconductors using a plane-wave basis set. Comput. Mater. Sci. 6(1), 15 (1996). DOI: 10.1016/ 0927-0256(96)00008-0.

[18] G. Kresse, and D. Joubert, From ultrasoft pseudopotentials to the projector augmentedwave method. Phys. Rev. B. 59(3), 1758 (1999). DOI: 10.1103/PhysRevB.59.1758.

[19] G. Kresse, and J. Furthmüller, Efficient iterative schemes for ab initio total- energy calculations using a plane-wave basis set. Phys. Rev. B. 54(16), 11169 (1996). DOI: 10.1103/ PhysRevB.54.11169.

[20] P. Hohenberg, and W. Kohn, Inhomogeneous Electron Gas. Phys. Rev. 136, A1133 (1964).

[21] J. P. Perdew, S. Burke, and M. Ernzerhof, Generalized gradient approximation made simple. Phys. Rev. Lett. 77(18), 3865 (1996). DOI: 10.1103/PhysRevLett.77.3865.

[22] H. J. Monkhorst, and J. D. Pack, Special points for Brillouin-zone integrations. Phys. Rev. B. 13(12), 5188 (1976). DOI: 10.1103/PhysRevB.13.5188.

[23] M. Yamaguchi, T. Furuta, and M. Ishikawa, Calorimetric study of several cuprates with restricted dimensionality. J. Phys. Soc. Jpn. 65(9), 2998 (1996). DOI: 10.1143/JPSJ.65.2998.

[24] Y. Le Page, and P. Saxe, Symmetry-general least-squares extraction of elastic coefficients from ab initio total energy. Phys. Rev. B. 63, 174103 (2001).

[25] O. Beckstein, et al., First-principles elastic constants and electronic structure of $\alpha-\mathrm{Pt}_{2} \mathrm{Si}$ and PtSi. Phys. Rev. B. 63, 134112.1 (2001).

[26] D. C. Wallace, Thermodynamics of Crystals (New York: Wiley, 1972).

[27] W. Voigt, Lehrbuch Der Kristallphysik (Leipsig: Teubner, 1928), 962

[28] A. Reuss, Berechnung der fließgrenze von mischkristallen auf grund der plastizitatsbedingung $\mathrm{f}$ " ur einkristalle. $Z$ Angew. Math. Mech. 9(1), 49 (1929). DOI: 10.1002/ zamm.19290090104.

[29] R. Hill, The elastic behavior of crystalline aggregate. Proc. Phys. Soc. A. 65(5), 349 (1952). DOI: $10.1088 / 0370-1298 / 65 / 5 / 307$.

[30] V. V. Bannikov, I. R. Shein, and A. L. Ivanovskii, Electronic structure, chemical bonding and elastic properties of the first thorium-containing nitride perovskite $\mathrm{TaThN}_{3}$. Phys. Stat. Sol. (Rrl). 1(3), 89 (2007). DOI: 10.1002/pssr.200600116.

[31] H. Koc et al., Ab initio calculation of the structural, elastik, electronic, and linear optical properties of $\mathrm{ZrPtSi}$ and TiPtSi ternary compounds. Comput. Mater. Sci. 62, 235 (2012). DOI: 10.1016/j.commatsci.2012.05.052.

[32] H. Koc et al., First principles prediction of the elastic, electronic, and optical properties of $\mathrm{Sb}_{2} \mathrm{~S}_{3}$ and $\mathrm{Sb}_{2} \mathrm{Se}_{3}$ compounds. Solid State Sci. 14(8), 1211 (2012). DOI: 10.1016/ j.solidstatesciences.2012.06.003.

[33] I. R. Shein, and A. L. Ivanovskii, Elastic properties of mono- and polycrystalline hexagonal $\mathrm{AlB}_{2}$-like diborides of $\mathrm{s}, \mathrm{p}$ and $\mathrm{d}$ metals from first-principles calculations. J. Phys: Condens. Matter. 20, 415218.1 (2008). DOI: 10.1088/0953-8984/20/41/415218.

[34] F. Pogh, Relations between the elastic moduli and the plastic properties of polycrystalline pure metals. Philos. Mag. 45, 823 (1954).

[35] D. H. Chung, and W. R. Buessem, In: Anisotropy in Single Crystal Refractory Compounds. Edited by Vahldiek FW, Mersol SA (New York: Plenum, 1968), 217.

[36] I. Johnston, et al., Solids State Physics Simulations, the Consortium for Upper Level Physics Software. (New York: Wiley, 1996). 
[37] O. L. Anderson, A simplified method for calculating the Debye temperature from elastic constants. J. Phys. Chem. Solids. 24(7), 909 (1963). DOI: 10.1016/0022-3697(63)90067-2.

[38] E. Schreiber, O. L. Anderson, and N. Soga, Elastic Constants and Their Measurements (New York: McGraw-Hill, 1973). 